\title{
Genetic legacy and the genomic future
}

\author{
Judith L. Benkendorf, MS, CGC1
}

\begin{abstract}
AT THE BEGINNING
My story starts in a ninth-grade biology class. There I was introduced to the principles of human genetics and several disorders in which they were exemplified. I loved the math and probability, the relationship between human variability and disease, and the notion declared by the course's teacher, Joan Heller, that "one day there will be health professionals who will help families understand disease risk and make tough choices." I was hooked.

At the University of Cincinnati in the mid-1970s, I met my first human genetics mentors. Dr Carl Huether, active in the American Society of Human Genetics (ASHG), saw human genetics through a societal lens and challenged us to think "big picture," including the importance of genetics education. Dr Lawrence Erway engaged me in basic research: we bred mice with a pigment mutation that had pleiotropic effects on otolith morphology, resulting in congenital ataxia. These mentors helped me realize both that I was intellectually curious and that I needed to work interactively with people.
\end{abstract}

When I entered the Human Genetics Program at Sarah Lawrence College in September 1978, genetic counseling was a small and nascent field: the National Society of Genetic Counselors (NSGC) was incorporated as I graduated; genetic counselors were called "genetic associates" in some circles; nondirective counseling was de rigueur; and the first set of board exams would be given in December 1981. There was excitement and uncertainty about the future-the opportunities were mine to seize and create.

My first job was at the Mailman Center for Child Development at the University of Miami School of Medicine. I joined a large clinical team in a "general genetic counseling" position. I saw it all: genetic diseases affecting people of all ages and all organs and physiological systems, in the culturally rich and socioeconomically mixed patient population that typified Miami. During those years, two insights shaped my future career. First, I realized that mentors from non-genetic disciplines who could bring depth to my training were necessary to my professional growth. I reached out to bioethicists and behavioral scientists, a hospital chaplain, medical communication experts, and members of the perinatal/neonatal nursing and social work bereavement teams, to name a few. Second, the more we identified common ground, the more opportunities I found where my genetic counseling skills were well suited to fill gaps in both clinical care and medical education.
Between 1982 and 1986, I became assistant professor of Medicine and helped design and coordinate a new 125-hour interdisciplinary, experiential behavioral science course required for first-year medical students (Health and Human Values). This resulted in my participation in medical education activities of the Association of American Medical Colleges. In 1983, I presented at a medical student education forum at the ASHG meeting, reporting on attitudinal changes in first-year medical students who followed a patient with a genetic diagnosis for a year. I joined ASHG's Information and Education Committee and its Task Force on Medical Education shortly thereafter. I was also asked to chair the committee that would write the Code of Ethics of the NSGC. As a clinician, I made myself known as a person who could work with families experiencing an abnormal prenatal diagnosis, stillbirth, or birth of a baby with congenital anomalies. I counseled, listened, casemanaged, and did all I could to ensure that the family would have continuous genetics support and answers to key questions. These patients and families are among my most memorable teachers. My professional life was interesting, rich, and rewarding. I was never bored.

\section{IN THE MIDDLE}

In late 1986, I began 15 years in the Department of Obstetrics and Gynecology's Division of Genetics at Georgetown University School of Medicine. Initially hired for my blended expertise in perinatal bereavement and genetic counseling, I also brought an unwavering commitment to national service (NSGC, ASHG, and later, the American College of Medical Genetics and Genomics and the American Board of Genetic Counseling). For this, I credit Joan Marks at Sarah Lawrence College, who instilled a commitment to be an advocate on all levels. I also found a second clinical home at DC General Hospital, in the district's only public prenatal care facility for alcohol- and drug-dependent women. (I later joined a colleague in establishing similar programs in Maori communities of New Zealand.)

I was continually engaged in teaching, discovery, and delivery of clinical care. As the Human Genome Project unfolded, I became intrigued by the bigger picture, particularly the ethical, legal, and social implications (ELSI). This led to becoming a coinvestigator on several projects carried out with the support of National Institutes of Health/ELSI-funded grants, which

${ }^{1}$ Office of the Executive Director, American College of Medical Genetics and Genomics, Bethesda, Maryland, USA. Correspondence: Judith L. Benkendorf (jbenkendorf@acmg.net) Submitted 19 February 2014; accepted 12 March 2014; advance online publication 24 April 2014. doi:10.1038/gim.2014.36 
(i) examined the impact of learning one's BRCA1/2 mutation status and (ii) assessed pre- and posttest education and counseling protocols. From this, I learned the importance of conducting genetic counseling research.

During my tenure as a director of the American Board of Genetic Counseling(1995-1999), I sought to improve the way counseling skills were assessed on national certification exams. I also realized that continuing education opportunities for genetic counselors focused more on genetics than on counseling. What was available to sharpen counseling skills as midcareer professionals? Ironically, I was now learning from the genetic counseling students I supervised. When one of them did something I would never have considered, I asked about motivation: they often learned it from one of my counselor colleagues. Coincidentally, a spark was lit by a National Public Radio interview with sociolinguist Dr Deborah Tannen on discourse, gender, and the use of direct and indirect speech in the workplace. As a result, a genetic counseling colleague, Michele Prince, sociolinguist Dr Heidi Hamilton, and I applied sociolinguistic research methods to study genetic counseling, funded by the Jane Engelberg Memorial Fellowship of the NSGC. Did our most valuable tool-talk-facilitate or hinder the use of genetic counseling principles? One finding was that overuse of indirect speech-a proxy for "non-directive genetic counseling"-was leaving our patients confused. ${ }^{1}$ This material was the substance of the first ASHG plenary session presentation made by a genetic counselor. Achieving this career goal was matched only by my being promoted to full professor.

\section{TO THE PRESENT}

With 2 decades of experience as a genetic counselor, I had a growing interest in policy issues and in becoming part of the solution. As the first genetic counselor awardee of an American Association for the Advancement of Science Congressional Fellowship (sponsored by ASHG), in 2000 I served on the professional staff of the Health Subcommittee of the Energy and Commerce Committee in the US House of Representatives. We had a broad charge that encompassed public health and biomedical issues. We wrote authorizing and regulatory legislation, worked to stop misguided policy, and conducted oversight investigations. Genetic counseling skills were instrumental in facilitating negotiations and decision making and in rendering information and complex principles into simple language.

After leaving "the Hill," I spent several years pursuing health services research. Most significant was the federally funded assessment of clinical genetic services and the medical genetics workforce. In early 2005, I joined the professional staff at the American College of Medical Genetics and Genomics, where I currently serve as the special assistant to the executive director. I use my genetic counseling skills daily, looking for ways to improve the delivery of genetic and genomic health care. I still teach graduate and undergraduate students. It is so important to infuse genetic and genomic thinking into the everyday lives of those just starting out!

\section{THE FUTURE: BUILDING THE COUNSELOME}

Since the 1990s, molecular biologists have been assembling "omes," from genomes to proteomes and metabolomes. "Omes" are known for encompassing the totality of a large field and are inherently dynamic. There is an expectation that the knowledge base will grow with new discoveries. By elevating the core principles that underpin the art and science of genetic counseling into a "counselome" and by making the acquisition and ongoing refinement of these skills an educational requirement, genetic counseling is now on par with other genetic and genomic disciplines and their companion "omes."

In 1997, Dr Seymour Kessler differentiated education (often the end point of informed consent) from counseling in the context of genetic decision making. ${ }^{2}$ The former uses the retention of correct information as its end point; the latter is concerned with how people use their past experiences, values, beliefs, strengths, goals, and other resources to adapt to new information and integrate it into the fabric of their lives. The genetic counselor does more than provide patients and families with accurate, balanced factual information: through a mutual process, new meaning is found in the genetic information. It is precisely with the tools of a 21st-century counselome that we can ensure that people are prepared for the genomic information they receive. Above all, this is a call to action for genetic counselors-and their medical geneticist and clinical geneticist colleagues - to find improved ways to meet patient needs and maintain standards of care in the genetic setting. Along the way, it will be imperative to work collaboratively with social and behavioral science researchers and multimedia education experts.

Over the years, I have worn many hats; but with each one, I have consistently identified myself as a genetic counselor. For me, genetic counseling, as both an activity and a profession, is a key to maximizing the promise of genomic health care.

\section{ACKNOWLEDGMENTS}

The author thanks Dr Meredith Weaver for the insights provided by her critical review of the manuscript.

\section{DISCLOSURE}

The author declares no conflict of interest.

The views expressed in this article are the author's own and do not reflect those of the American College of Medical Genetics and Genomics.

\section{REFERENCES}

1. Benkendorf JL, Prince MB, Rose MA, De Fina A, Hamilton HE. Does indirect speech promote nondirective genetic counseling? Results of a sociolinguistic investigation. Am J Med Genet 2001;106:199-207.

2. Kessler S. Psychological aspects of genetic counseling. IX. Teaching and counseling. J Genet Counsel 1997; 6:287-295. 